\title{
Auditory Brain Stem of the Ferret: Some Effects of Rearing with a Unilateral Ear Plug on the Cochlea, Cochlear Nucleus, and Projections to the Inferior Colliculus
}

\author{
David R. Moore, Mary E. Hutchings, Andrew J. King, and Nancy E. Kowalchuk \\ University Laboratory of Physiology, Oxford OX1 3PT, United Kingdom
}

To examine the influence of acoustic experience on the development of the mammalian auditory brain stem, darkly pigmented ferrets were reared with a plug inserted in the right outer ear. The plugs were first inserted on postnatal day 2334 and produced a variable, frequency-dependent attenuation of up to $60 \mathrm{~dB}$. Between 3-15 months after the ear plug was begun, animals were prepared for physiological recording and injection of wheat germ agglutinin-HRP (WGAHRP) in the left inferior colliculus (IC). The plug was removed and the condition of the right ear was assessed by puretone stimulation and recordings from neurons in the left IC. Neural audiograms for each animal showed a residual deficit in most cases. Following $24-60 \mathrm{hr}$ survival, the animals were perfused and the right ear was examined. Brain-stem sections were reacted with tetramethylbenzidine. Outer and/or middle ear pathology was present in over half of the animals. However, the cochleas appeared to be normal and the spiral ganglion cells were normal by several quantitative criteria: number, area, and nucleolar eccentricity. The volume of each division of the cochlear nuclei (CN) and the areas of individual neurons in the anteroventral $\mathrm{CN}$ were the same on the right and left sides. The number of $C N$ neurons retrogradely labeled from the left IC injection of WGA-HRP was found to be significantly increased in the left $\mathrm{CN}$, relative to normal animals, when expressed as a ratio of the number labeled in the right $\mathrm{CN}$. We conclude that the residual hearing loss in the previously plugged ears was predominantly or exclusively conductive. Neonatal, unilateral conductive hearing loss in the ferret does not lead to degeneration of the $\mathrm{CN}$ on the side of the loss, but it does lead to at least one rearrangement of auditory brain-stem connectivity. We suggest that the extent to which the brain stem is modified by early auditory deprivation is dependent on the type, degree, and symmetry of the hearing loss.

The role of sensory experience in the development of the brain has been intensively studied over the last 25 years since Wiesel and Hubel first showed that deprivation of form vision in one eye of the neonatal cat leads to atrophy of ncurons in the latcral

Received Feb. 1, 1988; revised Aug. 1, 1988; accepted Aug. 2, 1988.

This research was supported by grants from the Medical Research Council, the Lister Institute for Preventive Medicine, and the E. P. Abraham Research Fund. We thank Simon Carlile and Ken Stratford for writing the computer programs to calculate Fourier transforms and nucleolar eccentricity. Mike Hawken and Mike Stryker provided valuable comments on the manuscript.

Correspondence should be addressed to Dr. D. R. Moore, University Laboratory of Physiology, Parks Road, Oxford OX1 3PT, UK.

Copyright (C) 1989 Society for Neuroscience $0270-6474 / 89 / 041213-10 \$ 02.00 / 0$ geniculate nucleus (Wiesel and Hubel, 1963a) and to rearrangement of functional connections in the striate cortex (Wiesel and Hubel, 1963b). Although many of the effects on the brain of manipulation of the visual environment are now well documented (e.g., see Sherman and Spear, 1982), little is known about the importance of a normal acoustic environment for the development of the central auditory system, particularly in mammals. There would appear to be 2 major reasons for this deficit of knowledge. First, the acoustic environment of an animal is impossible to control with any precision because of self-produced sounds and the confounding influence of boneconducted stimulation (see Moore, 1983). Second, attempts to restrict airborne sound stimulation by reversible manipulations of the outer ear have almost invariably produced irreversible pathology of the manipulated ear, when this has been examined using electrophysiological techniques (Silverman and Clopton, 1977; Moore and Irvine, 1981; Brugge et al., 1985). Nevertheless, there have been several claims that rearing with a unilateral conductive hearing loss can produce changes in the morphology (Killackey and Ryugo, 1977; Coleman and O'Connor, 1979; Webster and Webster, 1979; Feng and Rogowski, 1980; Conlee and Parks, 1981; Coleman et al., 1982; Smith et al., 1983; Webster, 1983) or physiology (Clopton and Silverman, 1977; Silverman and Clopton, 1977; Moore and Irvine, 1981; Knudsen, 1983, 1985; King et al., 1988) of the auditory brain stem.

In a recent report, Tucci and Rubel (1985) found that neuron shrinkage in the chicken nucleus magnocellularis (NM, an avian cochlear nucleus) occurred after rearing with a sensorineural hearing loss (oval window puncture) but not after rearing with a conductive loss (ear plug or columella removal). Unlike previous studies, Tucci and Rubel (1985) attempted to separate the conductive and sensorineural components of their manipulations by using bone stimulation and physiological recording of the output from the manipulated ear. They attributed the difference between their results and those of the studies cited above to 1 of 2 factors. Either the earlier researchers had inadvertently produced a sensorineural hearing loss or species differences existed in the response of cochlear nucleus $(\mathrm{CN})$ neurons to acoustic deprivation.

In order to clarify some of these issues we have reared ferrets with a unilateral (right) ear plug. Following this rearing we have examined the physiological output of the right ear, the histology of the right cochlea, the $\mathrm{CN}$ on both sides of the brain, and the projections from each $\mathrm{CN}$ to the left inferior coiliculus (IC). Projections from the $\mathrm{CN}$ to the IC have previously been shown to be altered by rearing with a unilateral cochlear lesion (Nordeen et al., 1983; Moore and Kitzes, 1985; Moore and Kowal- 
chuk, 1988), and we were interested to know if brain-stem connectivity might also be altered by a unilateral conductive loss.

\section{Materials and Methods}

Ear plugs. Neonatal ferrets $(n=13)$ were obtained from darkly pigmented parents by timed pregnancies and deliveries in the laboratory animal house. Unilateral ear plugs were inserted in the right ear on postnatal day (P) 23-34, where $\mathbf{P 0}$ is the day of birth. Functional onset of hearing in the ferret occurs around P32 (Moore, 1982), so the animals had, in all but one case (see Table 1), no experience of normal hearing in the plugged ear. The plug consisted of a polymeric based hearing aid impression compound (Starkey Laboratories Ltd., Handforth, Cheshire). Initially, before the opening of the external meatus, the plugs were used to fill the concha and other convolutions of the outer ear. When the meatus opened, plugs were made that also partially (about 5-6 $\mathrm{mm}$ ) filled the meatus. In the later experiments $(n=6)$, a small cube $(4 \times 4$ $\times 4 \mathrm{~mm}$ ) of compressible E.A.R. hearing protection sponge (Cabot Safety Ltd., Cheshire) was threaded with a sterile suture and incorporated into the impression compound on the proximal side of the plug. In all cases the plugs were attached at the concha margin using cyanoacrylate adhesive. The adhesive did not appear to produce any irritation of the skin and served to maintain a tight seal between the plug and the outer ear. Plugs were inspected daily and changed as often as was necessary to maintain a tight seal; around once per week on average. $\Lambda$ nimals were placed under general anesthesia [alphaxalone-alphadolone acetate (Saffan, Glaxovet); $1.2 \%$ total wt $/ \mathrm{vol} ; 2 \mathrm{ml} / \mathrm{kg}$, i.m.] for plug changing.

The attenuating effect of ear plugs of the type used was tested in experiments on normal, adult animals. Two procedures were used. In the first, 2 animals were anesthetized with Saffan and prepared for the recording of neuronal activity in the left IC, as detailed below and elsewhere (Moore et al., 1983, 1984). To prevent acoustic cross-talk from the unplugged ear, the left cochlea was extensively damaged via a ventral approach to the bulla (Moore and Kowalchuk, 1988). The animal was held in a stereotaxic frame and the dorsal surface of the left IC was exposed by aspiration of the overlying cortex. The head was attached to a support mounted behind the animal. Following removal of the stereotaxic frame, the ferret was placed in an anechoic, soundattenuating chamber containing a free-field sound delivery system (Annetts et al., 1987; King and Hutchings, 1987). Pure-tone stimuli were delivered with the speaker placed on the acoustic axis (Addison, 1984; Moore et al., 1984) of the right ear. A tungsten microelectrode was lowered through the dorsoventral extent of the central nucleus of the left IC. Neuronal activity (usually multiunit) was amplified and monitored on an oscilloscope and an audio channel. At intervals of 100-300 $\mu \mathrm{m}$ frequency-threshold determinations ("tuning curves") were made. Following an electrode penetration in which neurons were recorded with best frequencies in every octave of the ferret's audible range (Moore et al., 1983; Kelly et al., 1986), a plug was inserted in the right ear and the electrode was withdrawn, again recording at 100-300 $\mu \mathrm{m}$ intervals. Neural "audiograms" (the envelope of the frequency-threshold curves obtained at each recording position) were constructed for "plug in" and "plug out" conditions. In one of these experiments the ear plugs contained the additional E.A.R. sponge (see above).

The second procedure for measuring the attenuating effect of the ear plugs was, initially, to anesthetize the ferret $(n=2)$ and prepare the head support, as above. A small (1-mm-diameter) slit was made in the wall of the external auditory meatus, about $10-15 \mathrm{~mm}$ proximal to the tragus, via a surgical approach posterior to the pinna through the tissue overlying the bulla. A $1 / 2$ inch probe microphone (see Moore et al., 1983) was introduced into the slit, through the surgical wound, so that the probe tube tip was positioned within the lumen of the meatus and the microphone and associated electronics were held behind the animal's ear, flush against the neck. The probe tip was sealed into the meatus using cyanoacrylate, and the surgical wounds were tightly sutured. The animal was positioned in the center of the anechoic chamber and measurements were made of the sound pressure level in the probe tube tip with and without an ear plug (no E.A.R. sponge) in position. Pure-tone stimuli $(1 / 3$ octave intervals from 1.0 to $25.0 \mathrm{kHz}$ ) were delivered via the free-field transducer positioned along the acoustic axis of the pinna, as described above. In one experiment, the plugs were also tested using a transient (click) stimulus. A digitally controlled fast-Fourier transform on the averaged $(\times 1000)$ voltage signal from the microphone enabled a high-resolution estimate of the plug attenuation in this case.
Physiolugy of plugged ear. Between 3-15 months after the plug was first inserted animals were anesthetized with Saffan and prepared for recording in the left IC, as detailed above. The plug was removed from the right ear and the outer ear was examined. A fresh plug was placed in the left, previously unplugged ear to reduce acoustic cross-talk. Anesthesia was maintained with sodium pentobarbital (Nembutal, $1 \mathrm{mg}$ / $\mathrm{kg} / \mathrm{hr}$, i.v.) and paralysis (gallamine triethiodide, $20 \mathrm{mg} / \mathrm{kg} / \mathrm{hr}$, i.v.) was induced preparatory to a separate experiment described elsewhere (King et al., 1988). A sound-delivery system incorporating a probe microphone assembly (Fig. 2A; Moore et al., 1983) was fitted into the meatus of the right ear and was used to deliver pure-tone stimuli. Electrode penetrations were made through the left IC, and a neural audiogram was obtained. Two normal adult animals with pathology-free outer and middle ears were also tested in this manner and their audiograms, together with the 2 obtained from the animals described in the IC experiments of the previous section, provided control data.

Tracer injection. Following audiometry, the recording electrode was removed and $10 \%$ wheat germ agglutinin conjugated to HRP (WGAHRP, Sigma) was injected into the left IC, through the dorsal surface, as described in detail elsewhere (Moore, 1988a). Briefly, the WGA-HRP solution (200-300 nl) was introduced into a calibrated glass micropipette and ejected by air pressure at 6-8 sites widely spaced through the IC The time taken to deliver the WGA-HRP varied from 25 to $35 \mathrm{~min}$. Animals were maintained under deep anesthesia for a further $24-60 \mathrm{hr}$ while another physiological experiment (King et al., 1988) was performed. The EEG was monitored throughout this period and supplementary doses of anesthetic were administered when necessary (King and Hutchings, 1987). At the termination of recording the ferrets were given a further dose of Nembutal (at least $10 \mathrm{mg} / \mathrm{kg}$ ) and perfused transcardially with PBS, fixative (1\% formalin, $1.25 \%$ glutaraldehyde in PBS), and $10 \%$ sucrose in phosphate buffer.

Cochlear histology. The procedure and rationale for examination of the cochlea and counting of ganglion cells were based on those described in detail elsewhere (Moore and Kowalchuk, 1988). The temporal bones from the same side as the ear plug were removed from the aldehydefixed heads and carefully opened. Following inspection of the external auditory meatus, tympanic membrane, and middle ear, the cochlea was dissected out, postfixed, decalcified, embedded in paraffin, and sectioned at $10 \mu \mathrm{m}$ along a modiolar plane. One in six sections was mounted and stained with hematoxylin and eosin. All stained sections of every cochlea were inspected under high magnification $(\times 500)$ for signs of pathology. Ganglion cells containing a nucleolus were counted in the section that most closely bisected the whole cochlea. Ten cochleas from nondcprived ears were available for comparison.

The validity of this counting procedure was checked by randomly selecting 4 normal cochleas and counting the number of ganglion cells in every 6 th stained section (between 6 and 9 sections in all) through the whole cochlea. This sum was multiplied by the total number of stained sections through the cochlea and divided by the number of counted sections to yield an estimate that was free of any bias that may have been introduced by variations in the geometry of the cochlea and/ or in the cutting angle. In addition, this extended counting procedure was performed on the right cochleas from 2 ear-plugged animals (8628, 86-32) that were found to have middle ear detritus (see Results).

Ganglion cell areas were measured in midmodiolar sections from the 10 normal cochleas and the right cochleas of ferrets 86-28 and 86-32. Drawings of ganglion cclls showing the positions of the nucleolus within each cell were made in the focal plane of the nucleolus via a $100 \times$ objective. The drawings were digitized and processed through commercial software to compute areas and perform statistical analyses. Nucleolar eccentricity was measured for at least 50 ganglion cells, sampled from all turns, in each of 3 cochleas (one normal, 86-28 right, and 86-32 right). The normal cochlea chosen (85-121, left) was that for which the midmodiolar count of ganglion cells was closest to the sample mean. For each cell an equivalent circle was computed using a locally written program. The center of gravity of this circle served as the reference point from which the percentage eccentricity of the center of the nucleolus was calculated relative to the perimeter of the circle

Labeled cell counts. Following perfusion the brain stems were blocked, removed from the skull, and placed in $30 \%$ sucrose in phosphate buffer overnight. Frozen frontal sections $(40 \mu \mathrm{m})$ were cut and cvery third one was reacted by a modification of the tetramethylbenzidine method of Mesulam (1982), mounted, counterstained with neutral red, and coverslipped. The position of labeled neurons in each $\mathrm{CN}$ was reconstructed using a microscope fitted with a drawing tube. Counts of labeled neurons 
were corrected for uncounted sections (see Moore, 1988a). Results from 10 normal animals and 12 animals reared with unilateral cochlear lesions were available from earlier studies (Moore, 1988a; Moore and Kowalchuk, 1988). To reduce variability associated with differences in the criteria for counting a given cell, all the counts were made by a single observer. Because of the nature of the experiment, it was not possible for the observer to perform the counts "blind." However, evidence that there was no progressive bias to the counts is provided by the fact that the mean laterality index (see the Results) for the first 6 expcriments (85-109 to 86-42) was slightly greater (2.89) than that for the second 6 experiments $(86-47$ to $86-86 ; 2.72)$. Other aspects concerning the reliability of the counting technique have been discussed previously (Moore, 1988a).

Cochlear nucleus morphometry. Drawings of each of the 3 principal divisions of the $\mathrm{CN}$ (the anteroventral, AVCN; the posteroventral, PVCN; the dorsal, DCN) on both sides of all animals were outlined on a digitizing pad. The definitions of the divisions of the ferret $\mathrm{CN}$ have been presented in detail in a previous report (Moore, 1988a). In the present study, neither the granule cell layers nor the auditory nerve root were included in the measurements. The total volume of each $\mathrm{CN}$ was computed by summing the section areas and multiplying by $120 \mu \mathrm{m}$, the separation between the same frontal-plane face of each adjacent, processed section. Further details concerning the calibration and accuracy of this procedure are reported elsewhere (Moorc and Kowalchuk, 1988).

Measurements were made of neuron cross-sectional area in the AVCN of ferrets 86-28 and 86-32. For both sides of each brain, the 2 processed sections that were nearest to $1 / 3$ and $2 / 3$ of the rostrocaudal extent of the AVCN were chosen. The coverslips were removed and the sections were hydrated, stained in cresyl violet, dehydrated, and recoverslipped. Neurons were identified under high magnification $(\times 500$ total; NPL Fluotar $\times 40$ objective, n.a. 0.70 ) by the presence of a nucleolus, an agranular nucleus, a clear nuclear membrane and relatively abundant cytoplasm within a well-defined cytoplasmic membrane. Granule cells (Osen, 1969) were not measured. All neurons in each section were drawn through a camera lucida at the focal plane of the nucleolus and digitized using a Summagraphics Bitpad 2. Commercial software was used to calculate neuron areas and to perform statistical analyses.

\section{Results}

The attenuation produced by the ear plug (Fig. 1) varied with stimulus frequency, between animals, with time after insertion of the plug and with repeated replacement in the same animal. However, the 2 measurement techniques yielded similar results. Maximum attenuation varied between 33 and $58 \mathrm{~dB}$ in the 4 adults receiving an acute ear plug. In all cases low-frequency attenuation was less than that at high frequencies and, without the E.A.R. sponge, was around zero for frequencies less than 2 $\mathrm{kHz}$. The E.A.R. sponge increased attenuation across most of the frequency range, particularly at low frequencies. The attenuation mostly peaked at around $8 \mathrm{kHz}$ (Fig. 1A), but, as the high resolution measurements revealed (Fig. $1 B$ ), high-frequency notches also occurred. In summary, these data suggested a frequency-dependent attenuation of $10-40 \mathrm{~dB}$, with fluctuations either side of that range.

\section{Condition of plugged ear}

Only 4 of the 13 ferrets reared with plugs had outer and middle right ears that looked clean and normal when inspected using an operating microscope (Table 1). A further 6 animals had pathology that appeared to be restricted to a partial or total occlusion of the external auditory meatus. These occlusions consisted of a constriction of the walls of the meatus, an accumulation of detritus in the meatal lumen, or both conditions. Two other ferrets (86-28, 86-32; Tables 1,2$)$ had, in addition to outer ear pathology, an accumulation of material in the middle ear. Clearing of the middle ear post mortem revealed an intact and normal-looking set of ossicles and cochlea. The auditory periphery of these 2 ferrets was examined in great detail (Table 2)

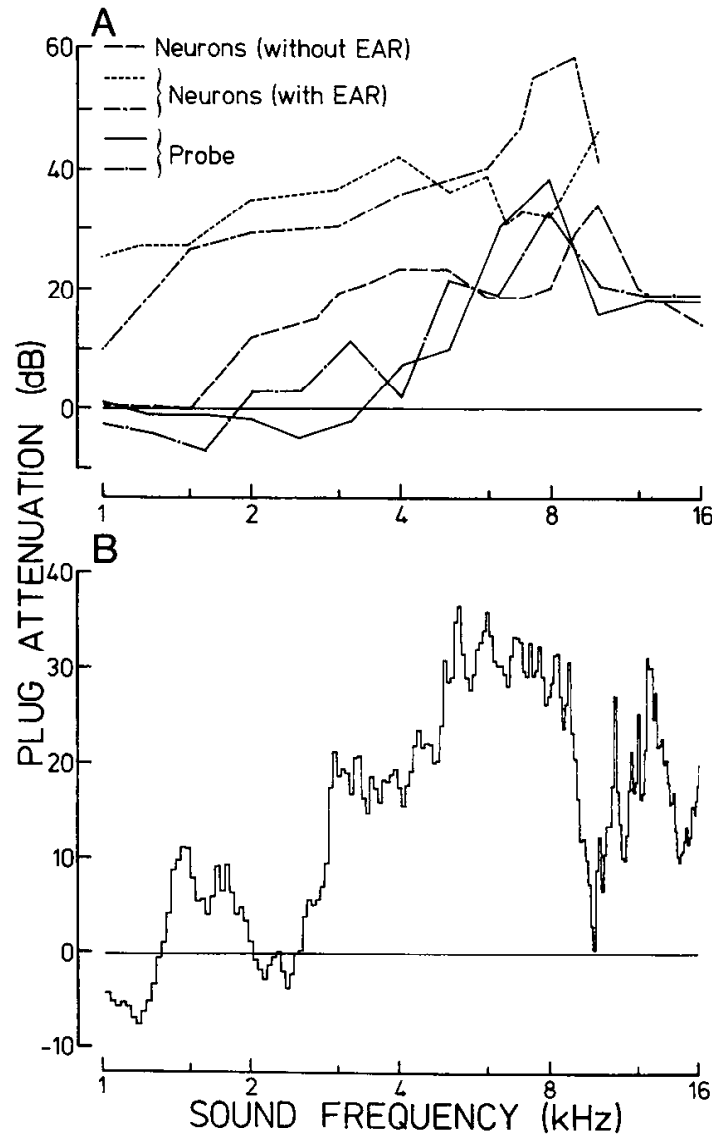

Figure 1. Attenuating effect of earplugs. Each curve shows the difference in measurements made before and after the insertion of plugs of the types used experimentally in the outer ear of a normal adult ferret. $A$, Pure-tone stimulation $(n=4)$. In one experiment (with $E A R$ ), the plugs included the E.A.R. sponge, and in the remaining experiments they did not. Two complete sets of readings were obtained in the with $E A R$ experiment in order to assess intra-animal variability. Neurons, experiments employing neural audiograms; Probe, experiments employing probe microphone readings (see text). $B$. Click stimulation ( $n$ $=1$ ). Fast-Fourier transforms (before and after plugging) of the probe microphone signal were performed at $81 \mathrm{~Hz}$ resolution and subtracted to yield these data.

since, it was reasoned, they were the ones most likely to have experienced a sensorineural hearing loss. Finally, one ferret had a cochlea that appeared to be damaged. This was confirmed when the cochlea was examined histologically, and that animal was excluded from any further analysis.

For the remaining 12 animals, the cochlea appeared to be normal, within the limitations of the histological technique. The organ of Corti was clean, and all major components, including the hair cells, were present in each turn of the cochlea. Mean counts of spiral ganglion cell bodies in the most medial section of the cochlea $(n=12, \bar{x}=245, s=56)$ did not differ significantly $(t=1.02, d f=20)$ from counts in the normal cochleas $(n=10$, $\bar{x}=225, s=20$ ), although the variance was somewhat greater in the ear-plugged group. Among individual animals (Table 1), there was no systcmatic relation between the visible extent of outer and middle ear pathology and the ganglion cell counts. Counting of ganglion cells in multiple sections (Table 2) led to the same conclusion. The number of ganglion cells in the right cochleas of ferrets $86-28$ and 86-32 were both within 1 SD of the mean counts from the 4 normal ears. Mean ganglion cell 
Table 1. Association between pathology of the outer and middle ear and the neural consequences of rearing with a plug of the right ear

\begin{tabular}{|c|c|c|c|c|c|c|c|}
\hline \multirow{2}{*}{$\begin{array}{l}\text { Type of } \\
\text { pathology }\end{array}$} & \multirow[b]{2}{*}{ Animal number } & \multicolumn{2}{|l|}{ Age at } & \multirow{2}{*}{$\begin{array}{l}\text { Threshold } \\
\text { elevation }\end{array}$} & \multirow{2}{*}{$\begin{array}{l}\text { Ganglion } \\
\text { cells } \\
\end{array}$} & \multirow[b]{2}{*}{$\mathrm{CN}$ volume } & \multirow{2}{*}{$\begin{array}{l}\text { Laterality } \\
\text { index } \\
(100 \mathrm{I} / \mathrm{C})\end{array}$} \\
\hline & & Plugging & Experiment & & & & \\
\hline \multirow[t]{4}{*}{ None } & $86-30$ & P23 & P307 & - & 238 & 0 & 3.03 \\
\hline & $86-48$ & P23 & P405 & 38 & 288 & 0 & 2.62 \\
\hline & $86-51$ & $\mathrm{P} 23$ & P412 & 9 & 267 & -2 & 2.67 \\
\hline & $86-86$ & $\mathrm{P} 25$ & P130 & 5 & 165 & +5 & 1.99 \\
\hline \multirow{6}{*}{$\begin{array}{l}\text { External } \\
\text { ear only }\end{array}$} & $85-109$ & P28 & $\mathrm{P} 122$ & - & 272 & -11 & 3.92 \\
\hline & $86-47$ & P23 & P398 & 48 & 249 & +3 & 2.71 \\
\hline & $86-81$ & P28 & P119 & 27 & 280 & -5 & 3.90 \\
\hline & $86-84$ & P28 & P126 & 34 & 280 & +16 & 2.44 \\
\hline & $85-159$ & P24 & P296 & 41 & 152 & -1 & 2.42 \\
\hline & $86-42$ & P23 & P363 & 49 & 343 & -7 & 2.00 \\
\hline \multirow{2}{*}{$\begin{array}{l}\text { External and } \\
\text { middle ear }\end{array}$} & $86-28$ & P24 & P470 & 25 & 204 & -7 & 3.01 \\
\hline & $86-32$ & P34 & P529 & 40 & 196 & +6 & 2.97 \\
\hline
\end{tabular}

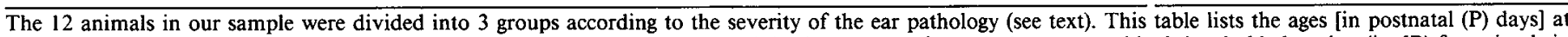

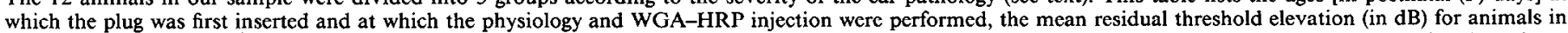

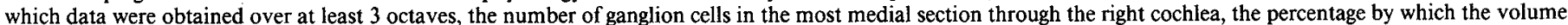
of the left $\mathrm{CN}$ exceeded that of the right $\mathrm{CN}$, and the laterality index (100I/C) for individual animals in each group.

areas in 86-28 and 86-32 (Table 2) were both about 1 SD $(s=$ 22) larger than the group mean of the 10 normal cochleas. Assuming that the variance associated with the normal measurements in these cases was a true reflection of the population variance, neither the number nor the area of ganglion cells in 86-28 or 86-32 differed significantly (by a $z$-score criterion) from the normal cochleas. Finally, mean nucleolar eccentricity, which has been found to change in neurons of the chicken NM following cochlear removal (Born et al., 1987), did not differ among ganglion cells in the 3 cochleas examined (Table 2). There is, therefore, no reason to believe that the cochleas in the previously plugged ears were pathological by any of the criteria examined.

Attempts were made to obtain neural audiograms for 11 of the ferrets reared with an ear plug. The remaining animal (85109) was used before these tests were developed. Thresholds to stimulation of the previously plugged ears were gencrally clevated, relative to those of normal animals (Fig. 2, Table 1). In the most extreme case (86-30), stimulus tones produced at the maximum intensity available (Fig. $2 A$ ) could evoke only weak neural responses in the contralateral IC. The reason for this

Table 2. Cochlear ganglion cell area, number, and nucleolar eccentricity, and AVCN neuron area in selected animals

\begin{tabular}{|c|c|c|c|c|c|c|c|c|c|}
\hline & \multicolumn{3}{|c|}{ Cell areas $\left(\mu \mathrm{m}^{2}\right)$} & \multicolumn{3}{|c|}{ Cell numbers ( $1: 6$ series) } & \multicolumn{3}{|c|}{$\begin{array}{l}\text { Nucleolar } \\
\text { eccentricity (\%) }\end{array}$} \\
\hline & $n$ & $\bar{x}$ & $s$ & $n$ & $\bar{x}$ & $s$ & $n$ & $\bar{x}$ & $s$ \\
\hline \multicolumn{10}{|c|}{ Cochlcar ganglion cclls } \\
\hline \multirow[t]{2}{*}{ Normal ears } & $234^{a}$ & $150^{a}$ & $35^{a}$ & $(4)$ & 4555 & 866 & 78 & 45 & 21 \\
\hline & $(10)$ & $150^{a}$ & $22^{b}$ & & & & & & \\
\hline \multicolumn{10}{|l|}{ Plugged ears } \\
\hline $86-28$ & 204 & 173 & 45 & (1) & 4658 & - & 83 & 47 & 24 \\
\hline \multirow[t]{3}{*}{$86-32$} & 196 & 178 & 48 & (1) & 5224 & - & 89 & 52 & 31 \\
\hline & \multicolumn{3}{|c|}{ Cell areas (caudal) $\left(\mu \mathrm{m}^{2}\right)$} & \multicolumn{3}{|c|}{ Cell areas (rostral) $\left(\mu \mathrm{m}^{2}\right)$} & & & \\
\hline & $n$ & $\bar{x}$ & $s$ & $n$ & $\bar{x}$ & $s$ & & & \\
\hline \multicolumn{10}{|l|}{ AVCN neurons } \\
\hline \multicolumn{10}{|l|}{ Normal side } \\
\hline $86-28$ & 189 & 118 & 32 & 337 & 238 & 59 & & & \\
\hline $86-32$ & 206 & 141 & 37 & 223 & 203 & 77 & & & \\
\hline \multicolumn{10}{|l|}{ Plugged side } \\
\hline $86-28$ & 276 & 144 & 44 & 233 & 175 & 49 & & & \\
\hline $86-32$ & 152 & 165 & 55 & 214 & 207 & 54 & & & \\
\hline
\end{tabular}

Numbers $(n)$ in parentheses are the total number of cochleas examined. Other $n$ s are the number of neurons measured or counted. $\bar{x}=$ mean; $s=\mathrm{SD}$. Further details are provided in the text.

"The means and SD for this condition are, respectively, the mean number of neurons measured in each cochlea, the mean of the individual animal means, and the mean of the individual animal SDs.

"The SD of the individual animal means. 


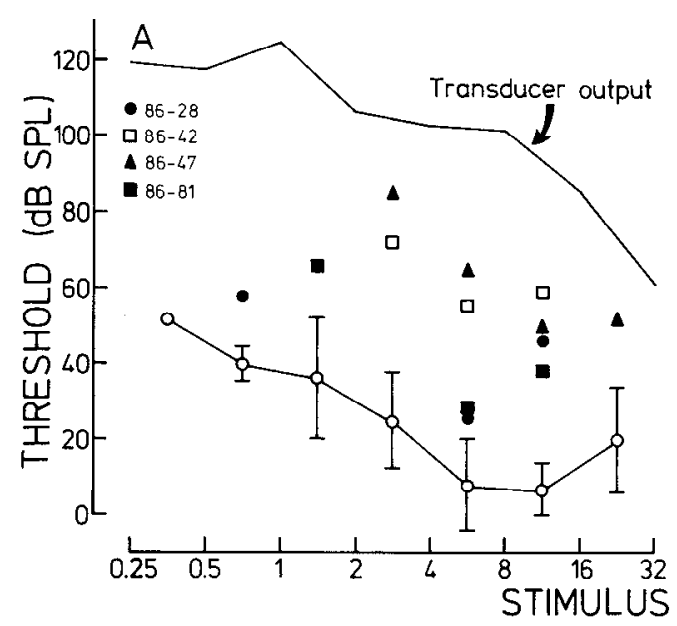

Figure 2. Physiology of normal [points with error ( \pm SD) bars] and previously plugged ears. Each point shows the threshold of the most sensitive neural response in the left IC to pure-tone stimulation of the right ear over the indicated octave frequency ranges. Stimuli were delivered by either a transducer/microphone assembly placed in the outer ear ("closed" system; Moore et al., 1983) or a free-field system (King

failure was unclear, since 86-30 had clean middle and outer ears. In another 4 cases, thresholds were only measured over limited frequency ranges (Fig. $2 A$ ). For these and the remaining 6 ferrets, whose neural audiograms are shown in Figure $2 B$, threshold elevations ranging from 0 to $60 \mathrm{~dB}$ were measured. No statistical correlation existed between the visible signs of outer and middle ear pathology and the audiograms recorded from the same ears (Table 1). However, the 2 audiograms that most closely resembled the normal mean (Fig. $2 B$ ) were both derived from animals with completely healthy looking ears (8651 and 86-86). Note that the ovcrall attenuation of sounds reaching the inner ears of animals during rearing consisted of both the attenuating effects of the ear plugs and that produced by the outer and middle ear pathology.

\section{Cochlear nucleus morphometry}

Volumetric measurements of each CN (Fig. 3) showed that rearing with an ear plug did not produce any mean decrease in the volume of the right $\mathrm{CN}$, or any of its divisions, relative to the left CN. In contrast, cochlear lesions at P22-P25 (Moore and Kowalchuk, 1988) produced a $28 \%$ mean reduction in the volume of the whole $\mathrm{CN}$ and a $34 \%$ reduction in the volume of the AVCN (Fig. 3). Comparisons between individual, ear-plugged animals also failed to show a reduction in the volume of the right $\mathrm{CN}$ that was related to the degree of outer or middle ear pathology (Table 1). All animals reared with a plug, including 86-28 and 86-32, fell within the range of variation for the group of normals (Fig. 3).

The effect of ear plugging and the consequent accumulation of detritus in the middle ear on $\mathrm{CN}$ neuron size was examined at 2 rostrocaudal levels of the AVCN in ferrets 86-28 and 8632 (Table 2). These data were rather variable due to the histological constraints of working with relatively thick, frozen-cut sections. Nevertheless, the results showed clearly that neurons in the rostral AVCN were larger than those in the caudal AVCN. In contrast, no consistent difference was observed between the plugged and unplugged sides.

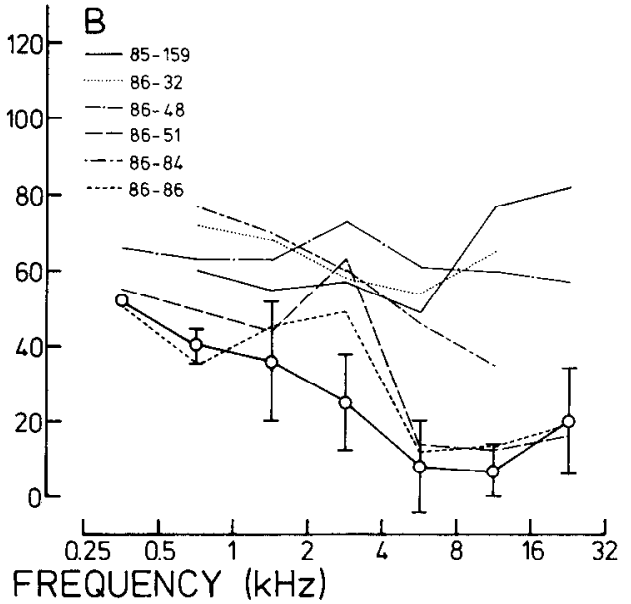

and Hutchings, 1987). A, Previously plugged ears for which measurements were obtained over less than 5 octaves. The maximum output level of the "closed" system, used to obtain all the data from these ears, is indicated by the dotted line. $B$, Neural audiograms from the previously plugged ears for which measurements were obtained over 5 or more octaves.

\section{Projections to the IC}

As reported elsewhere (Moore, 1988a; Moore and Kowalchuk, 1988), injections of WGA-HRP into one IC of normal or unilaterally cochlear-lesioned ferrets result in retrograde labeling of neurons in all identified auditory nuclei on both sides of the brain stem. In the $\mathrm{CN}$ of normal ferrets there is an asymmetry between the 2 sides of the brain in the number of projecting neurons, about 50 times as many projecting to the contralateral IC as to the ipsilateral IC (Figs. 4, 5). Following unilateral cochlear lesions at $\mathrm{P} 22-\mathrm{P} 25$, the number of $\mathrm{CN}$ neurons projecting to the ipsilateral IC on the unlesioned side of the brain increases by an average of $40 \%$ (Fig. 4 )

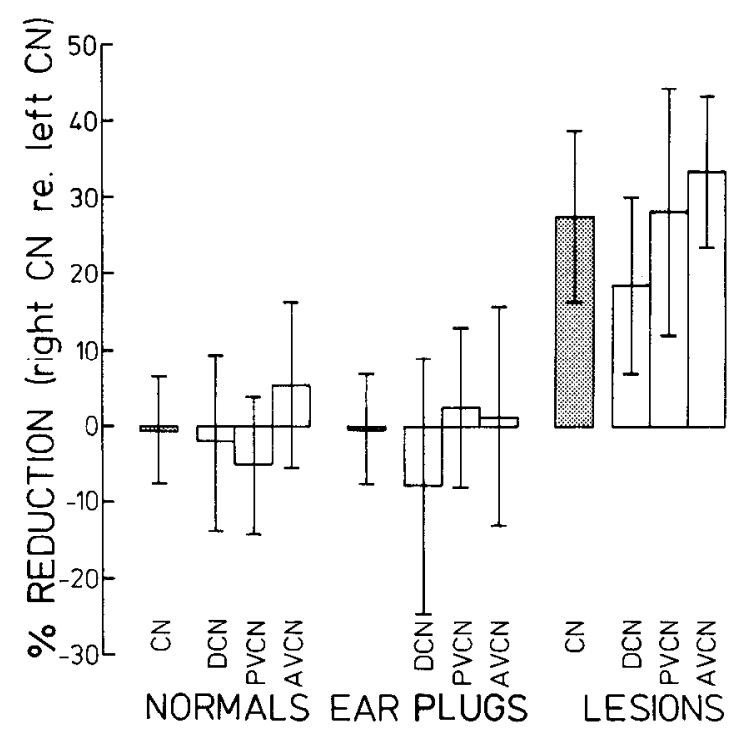

Figure 3. The mean $( \pm \mathrm{SD})$ volume reduction of the right (plugged/ lesioncd side) $\mathrm{CN}$ and each of its constituent divisions relative to the left $\mathrm{CN}$. 


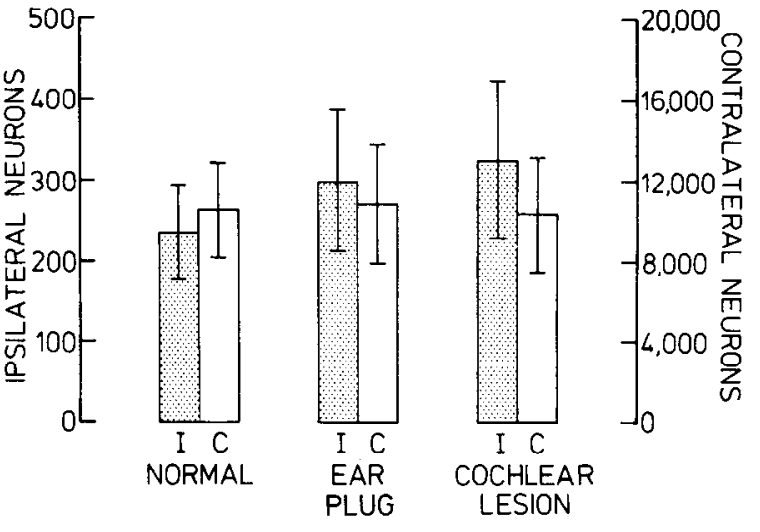

Figure 4. The mean $( \pm \mathrm{SD})$ number of retrogradely labeled neurons in each CN following injections of WGA-HRP in the left IC. Ipsilateral $=\mathrm{I}=$ left $\mathrm{CN}$; contralateral $=\mathrm{C}=$ right $\mathrm{CN}$.

Rearing with a unilateral ear plug also increased the mean number of $\mathrm{CN}$ neurons projecting to the ipsilateral IC on the side of the brain opposite the plugged ear (by 28\%, Fig. 4), although this increase did not achieve statistical significance $(t$ $=1.87 ; d f=20 ; p=0.08,2$-tailed test) due to the large variance associated with the mcan of the group of car-plugged animals. We have shown elsewhere (Moore, 1988a; Moore and Kowalchuk, 1988) that interanimal variation in the laterality of the projections from each $\mathrm{CN}$ to the IC can be reduced by expressing the number of labeled neurons in the $\mathrm{CN}$ ipsilateral to the injected IC as a ratio of the number labeled in the contralateral $\mathrm{CN}$. When this ratio was computed for the ear-plugged animals (Fig. 5), the variance was reduced and the mean "laterality index" (100I/C; Moore and Kowalchuk, 1988) differed significantly from that of the normal animals $(t=2.34 ; d f=20 ; p=$ 0.03 , 2-tailed test). Thus, rearing with a unilateral earplug in the ferret changed the symmetry of the projection from each $\mathrm{CN}$ to the IC. The symmetry change was entirely attributable to an increase in the number of labeled $\mathrm{CN}$ neutrons ipsilateral to the WGA-HRP injected IC; that is, on the side of the brain opposite the plugged ear. All divisions (DCN, PVCN, AVCN) of that $\mathrm{CN}$ contained increased numbers of labeled neurons, and no clear difference was found between or within divisions in their response to the rearing procedure. Elsewhere in the brain stem, labeled neurons were found in all auditory nuclei, as in normal animals. No qualitative difference was observed in those nuclei, although quantitative analyses were not performed outside the $\mathrm{CN}$.

Attempts to compare $\mathrm{CN}$ laterality indices among the 3 groups of ear-plugged ferrets having qualitatively different degrees of outer and middle ear pathology (Table 1) were somewhat thwarted by the small number of animals in each group. Nevertheless, the 2 groups with outer ear pathology had higher mean values $(n=8, \bar{x}=2.92, s=0.69)$ than the pathology-free group ( $n=4, \bar{x}=2.58, s=0.43$ ). These subgroups were tested against the data from the normal animals $(n=10, x=2.23, s=0.46)$ using an analysis of variance. The results revealed a small difference between the groups $(F=3.42, d f=2,19, p=0.05)$. Post hoc comparisons between individual means showed that the group with outer ear pathology differed significantly from the normals (Newman-Keuls test; $r=3, d f=19, q=3.74, p<$ 0.05 ), whereas neither of the other two comparisons (normal

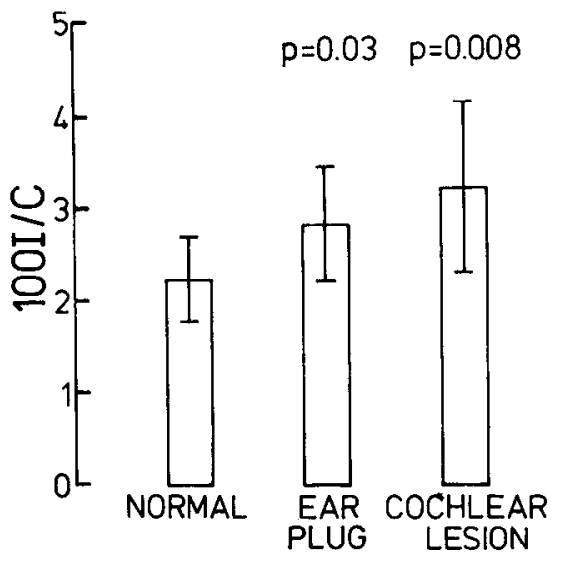

Figure 5. The mean $( \pm \mathrm{SD})$ ratio of retrogradely labeled neurons in the $\mathrm{CN}$ ipsilateral $(I)$ and contralateral $(C)$ to the injected 'IC. Ratios were multiplied by 100 only for convenience of presentation. Results of $t$ tests comparing each experimental group with the normals are shown.

and pathology-free, pathological and pathology-free) was significant. Taken in conjunction with the results from ferrets reared with a unilateral cochlear lesion (Figs. 4, 5; Moore and Kowalchuk, 1988), these data suggest that the extent to which neonatal hearing loss affects auditory brain stem organization is dependent on the degree of the hearing loss.

\section{Discussion}

\section{Type of hearing loss}

A pivotal issue in this study is whether the hearing loss produced by the ear-plugging procedure was purely conductive or included a sensorineural component. A conductive loss involves only a reduction in the amplitude of mechanical events leading to the initiation of nerve impulses, whereas a sensorineural loss involves some damage to the hair cells, spiral ganglion neurons, or higher levels, leading to an alteration in the discharge properties of auditory neurons. We believe that the ear plugs used in these experiments did not result in a sensorineural hearing loss, although we also believe that it is practically impossible to establish the purity of a conductive hearing loss with certainty.

A number of the results are relevant to this issue. First, there was the residual threshold elevation observed in the neural audiograms from most of the previously plugged ears. This may have been attributable to either a conductive or a mixed (conductive and sensorineural) loss. Second, we found apparently normal morphology in the cochleas of the plugged ears. This evidence is also inconclusive since it is possible that some damage, not detectable or not measured by the light microscopic techniques used, was done to either the hair cells or the ganglion cells. For instance, oval window puncture combined with columella removal does not reduce the number of hair cells in the chicken cochlea but does lead to the abolition of spontaneous activity in the cohclear nerve (Tucci et al., 1987), presumably as the result of a functional change in the hair cells or their synapse with the nerve fibers. Finally, neither the volume of the $\mathrm{CN}$ nor, in those cases tested, the size of neurons in the AVCN was reduced on the plugged side, and it is on the basis of those findings that the strongest claim may be made for the lack of a sensorineural component. It has recently been shown that oval window puncture (Tucci and Rubel, 1985) or application of 
TTX to the cochlea (Pasic and Rubel, 1987; Born and Rubel, 1988 ) results in as great a reduction of cell size in the NM or $\mathrm{CN}$ as does complete removal of the cochlea (Born and Rubel, 1985). Thus, peripheral manipulations that do not result in any observable mechanical damage to the cochlea, but do abolish cochlear nerve activity, lead to reductions in $\mathrm{CN}$ cell size. $\mathrm{CN}$ volume is a more convenient and, where comparisons have been made in the same laboratory, a more sensitive indicator of the atrophic effects produced by cochlear lesions than either cell size or number in the CN (Powell and Erulkar, 1962; Parks, 1979; Trune, 1982; Moore, 1988b; Moore and Kowalchuk, 1988). We would propose, therefore, that $\mathrm{CN}$ volume was the most sensitive morphological index used in this study and that the lack of a $\mathrm{CN}$ volume reduction on the side of the plugged ears is the strongest evidence against a sensorineural hearing loss. Nevertheless, it remains possible that some more subtle form(s) of sensorineural hearing loss do not lead to detectable $\mathrm{CN}$ volume reductions.

Tucci and Rubel (1985) have argued that bone stimulation may be used to segregate the conductive and sensorineural components of a hearing loss. Normal bone conduction thresholds accompanied by elevated air conduction thresholds (an "airbone gap") presumably indicate a purely conductive loss. However, an elevated bone conduction threshold does not necessarily imply a sensorineural component. Conductive factors such as changes in ossicular inertia produced by middle ear effusion or otosclerosis may affect bone conduction thresholds (Tonndorf, 1972; Steel et al., 1987). It therefore seems that bone stimulation can provide useful information only in some cases. In addition, there is doubt concerning the calibration of bone stimulators for tests on pathological ears. To define an air-bone gap it is necessary to express bone conduction thresholds relative to air conduction thresholds. However, in pathological ears, air conduction thresholds are, by definition, elevated. Therefore, bone conduction measurements in these ears must be referenced to bone conduction thresholds in normal ears, where air conduction thresholds are not elevated. Threshold tests in our laboratory on normal animals (M. E. Hutchings, unpublished observations), using a variety of bone stimulation configurations, have proved to be problematic since bone stimulators invariably also produce airborne sound.

\section{$C N$ degeneration}

As argued above, the results of this study suggest that a conductive hearing loss in the ferret does not produce whole nucleus or cell size reductions in the $\mathrm{CN}$. This finding is in accord with the study of Tucci and Rubel (1985) on the chicken NM but contrasts with earlier reports that rearing with a conductive hearing loss leads to reductions of cell size and/or number in the chicken NM (Conlee and Parks, 1981) or the mouse (Webster and Webster, 1977, 1979; Webster, 1983, 1988) or rat (Coleman and O'Connor, 1979; Coleman et al., 1982) CN. The suggestion (Tucci and Rubel, 1985) that species differences may account for these conflicting results seems less likely in view of the ferret data. The cytoarchitecture and connections of the ferret auditory brain stem (Moore, 1988a) resemble those of other mammalian species, including the mouse (Ryugo et al., 1981; Webster and Trune, 1982; Willard and Ryugo, 1982; Ryugo and Willard, 1985) and rat (Harrison and Irving, 1965, 1966; Beyerl, 1978) more closely than those of the chicken (Rubel and Parks, 1975; Jhavcri and Morest, 1982; Conlec and Parks, 1986). The most probable reason for the differences in the results of auditory deprivation is the difficulty in producing a conductive loss without a sensorineural component and the likelihood that a sensorineural component was involved in those cases where changes were reported.

A conductive hearing loss results in a reduction in the level of evoked activity in the cochlear nerve without any alteration in the level of spontaneous activity in the NM or cochlear nerve (Tucci et al., 1987). On the other hand, cochlear removal (Koerber et al., 1966), oval window puncture (Tucci et al., 1987), and TTX administration (Pasic and Rubel, 1987; Born and Rubel, 1988) all eliminate spontaneous activity in the nerve and all lead to cell loss and shrinkage in the CN or NM (Levi-Montalcini, 1949; Parks, 1979; Trune, 1982; Born and Rubel, 1985, 1988; Pasic and Rubel, 1987; Tucci et al., 1987; Moore, 1988b). It therefore seems that abolition of activity in the cochlear nerve, rather than damage to the cochlea per se, is the crucial element in producing degenerative responses in the $\mathrm{CN}$. Whether activity has to be completely eliminated or whether reductions in evoked activity can produce other changes in $\mathrm{CN}$ neurons are questions for future research.

\section{Brain-stem projections}

The change observed here in the laterality of projections to the IC is the first demonstration of which we are aware of a change in central auditory system projections consequent upon auditory experience. Several other studies have reported changes in the physiology or dendritic morphology of brain-stem neurons following rearing with a unilateral occlusion of the outer ear (ClopIon and Silverman, 1977, 1978; Silverman and Clopton, 1977; Moore and Irvine, 1981; Gray et al., 1982; Conlee and Parks, 1983; Knudsen, 1983, 1985; Smith et al., 1983; Clerici and Coleman, 1986; King et al., 1988) or in an altered sound environment (Clopton and Winfield, 1976; Margoliash, 1986; Wallhausser and Scheich, 1987). One report (Knudsen, 1985) has shown stability of the projection system linking 2 tectal nuclei in barn owls reared with ear plugs. However, these studies and behavioral demonstrations of the effects of rearing with ear plugs (Kerr et al., 1979; Knudsen et al., 1982, 1984a, b) do not address the issue of the neural circuitry underlying changes contingent on altered auditory experience. Furthermore, few of these studies have examined the peripheral consequences of the hearing loss. Experiments designed to examine the effects of rearing with a unilateral cochlear lesion on the connections of the auditory brain stem have shown that, in addition to an increase in the number (Nordeen et al., 1983; Moore and Kowalchuk, 1988 ) and/or terminal distribution (Moore and Kitzes, 1985) of $\mathrm{CN}$ neurons projecting ipsilaterally to the IC on the unoperated side, there are changes in the innervation of the superior olivary nuclei (Kitzes, 1986; Moore and Kitzes, 1987). Moreover, lesions that did not produce reductions in the number of cochlear spiral ganglion neurons but that did reduce $\mathrm{CN}$ volume (Moore and Kowalchuk, 1988) resulted in brain-stem connection changes. Thus, attributing plasticity in the central auditory system to the acoustic environment would at least seem to require an assessment of the physiological competence of the manipulated ear(s) or morphometric measurements of the $\mathrm{CN}$ on the manipulated side(s).

How do changes occur in the organization of the auditory brain stem without any pathology in the cochlea or CN? Unilateral conductive hearing loss reduces the level of airborne sound reaching one inner ear and creates an imbalance between the ears in the amount of evoked activity in the auditory nerves. 
Changes in brain connectivity might therefore reflect an alteration in either the level or balance of evoked neural activity from the 2 cars. Results from the visual system suggest that the balance of activity is the more crucial element. Deprivation of patterned visual stimulation of one eye during infancy results in wider-ranging functional synaptic rearrangements in the visual cortex (Wiesel and Hubel, 1963b) than does pattern deprivation of both eyes (Wiesel and Hubel, 1965). Recent attempts to control the relative activity levels in the 2 eyes, using TTX and eyelid suture, have produced conflicling results (Chapman et al., 1986; Greuel et al., 1987). However, there appears to be general agreement that, providing at least one of the eyes is sufficiently active, relative activity levels determine the formation of ocular dominance columns in the visual cortex. By analogy, we suggest that a competition may take place between the 2 ears for synaptic space on neurons in the IC and in other bilaterally innervated nuclei of the auditory system. In contrast to the maintenance of cell size and number in the $\mathrm{CN}$, both the presence (Koerber et al., 1966; Nordeen et al., 1983; Moore and Kowalchuk, 1988) and the relative level of activity in binaural pathways are important factors in the competition.

In order to explain the results of the present study, this competitive hypothesis requires that inputs derived from both ears synapse onto single IC neurons. Physiological studies (for reviews, see Aitkin, 1986; Irvine, 1986) leave no doubt that this is the case; the response of most IC neurons is influenced by separate stimulation of either ear. The anatomical basis of the competition is less clear, since there is no direct evidence for the separate sites of origin of individual axons synapsing with IC neurons. Regarding the projection from the $\mathrm{CN}$ to the IC, recent anterograde studies in the cat (Oliver, 1984, 1985, 1987) and gerbil (Moore and Kitzes, 1985) are consistent with the hypothesis of bilateral synapses onto single neurons. For example, both left and right AVCN axons form synapses in the lateral part of the central nucleus of the IC. These synapses are predominantly asymmetric contacts on medium- or small-size dendrites and form a relatively homogeneous population of endings (Oliver, 1987). However, IC neurons receive many inputs in addition to the direct ones from the CN (see Moore, 1988a), and it is possible that several or all of them participate in the competition.

The functional consequences of the experience-dependent change in auditory brain-stem connectivity shown in this study are not clear. Previous behavioral studies of rearing with a unilateral ear plug have tested subjects binaurally, either for sound localization (Knudsen et al., 1982, 1984a, b) or for frequency generalization (Kerr et al., 1979). However, unilateral deprivation may produce different functional effects in each ear. For example, neonatal ablation of one cochlea produces a number of brain-stem connectivity changes, including an increase in the contralateral, uncrossed CN-IC projection of the type shown here (Nordeen et al., 1983; Moore and Kowalchuk, 1988). Physiological studies of IC and auditory cortical neurons in contralaterally cochlear ablated animals have shown an increase in sensitivity and discharge level to stimulation of the ipsilateral (intact) ear (Kitzes, 1984; Kitzes and Semple, 1985; Reale et al., 1987). Unilateral eye enucleation during visual development has also been associated with an enhancement of sensitivity and spatial resolution in the remaining eye (Shook et al., 1985; Heywood et al., 1988). It may thus be a general rule that unilateral sensory deprivation early in life results in an increased level of sensitivity and discriminative capacity on the undeprived side.
However, validation of this hypothesis requires further physiological and behavioral experiments in animals reared with a conductive hearing loss.

\section{References}

Addison, P. D. (1984) Coding for auditory localization in the midbrain of the ferret. D. Phil. thesis, University of Oxford.

Aitkin, L. M. (1986) The Auditory Midbrain-Structure and Function in the Central Auditory Pathway, Humana, Clifton, NJ.

Annetts, C. S. J., B. P. A. Howse, M. E. Hutchings, and A. J. King (1987) A digitally controlled vertical hoop system for the presentation of free-field auditory and visual stimuli. J. Physiol. (Lond.) 382: $21 \mathrm{P}$.

Beyerl, B. D. (1978) Afferent projections to the central nucleus of the inferior colliculus in the rat. Brain Res. 145: 209-223.

Born, D. E., and E. W Rubcl (1985) Afferent influences on brain stem auditory nuclei of the chicken: Neuron number and size following cochlea removal. J. Comp. Neurol. 231: 435-445.

Born, D. E., and E. W Rubel (1988) Afferent influences on brain stem auditory nuclei of the chicken: Presynaptic action potentials regulate protein synthesis in nucleus magnocellularis neurons. J. Neurosci. 8: 901-919.

Born, D. E., C. S. Carman, and E. W Rubel (1987) Correcting errors in estimating neuron area caused by the position of the nucleolus. $J$. Comp. Neurol. 255: 146-152.

Brugge, J. F., S. S. Orman, J. R. Coleman, J. C. K. Chan, and D. P. Phillips (1985) Binaural interactions in cortical area AI of cats reared with unilateral atresia of the external ear canal. Hearing Res. 20:275287 .

Chapman, B., M. D. Jacobson, H. O. Reiter, and M. P. Stryker (1986) Ocular dominance shift in kitten visual cortex caused by imbalance in retinal electrical activity. Nature 324: 154-156.

Clerici, W. J., and J. R. Coleman (1986) Resting and high-frequency evoked 2-deoxyglucose uptake in the rat inferior colliculus: Developmental changes and effects of short-term conduction blockade. Dev. Brain Res. 27: 127-137.

Clopton, B. M., and M. S. Silverman (1977) Plasticity of binaural interaction II. Critical period and changes in midline response. J. Neurophysiol. 40: 1275-1280.

Clopton, B. M., and M. S. Silverman (1978) Changes in latency and duration of neural responding following developmental auditory deprivation. Exp. Brain Res. 32: 39-47.

Clopton, B. M., and J. A. Winfield (1986) Effect of early exposure to patterncd sound on unit activity in rat inferior colliculus. J. Neurophysiol. 39: 1081-1089.

Coleman, J. R., and P. O'Connor (1979) Effects of monaural and binaural sound deprivation on cell development in the anteroventral cochlear nucleus of rats. Exp. Neurol. 64: 553-566.

Coleman, J., B. J. Blatchley, and J. E. Williams (1982) Development of the dorsal and ventral cochlear nuclei in rat and effects of acoustic deprivation. Dev. Brain Res. 4: 119-123.

Conlee, J. W., and T. N. Parks (1981) Age- and position-dependent effects of monaural acoustic deprivation in nucleus magnocellularis of the chicken. J. Comp. Neurol. 202: 373-384.

Conlee, J. W., and T. N. Parks (1983) I ate appearance and deprivation-sensitive growth of permanent dendrites in the avian cochlear nucleus (Nuc. magnocellularis). J. Comp. Neurol. 217: 216-226.

Conlee, J. W., and T. N. Parks (1986) Origin of ascending auditory projections to the nucleus mesencephalicus lateralis pars dorsalis in the chicken. Brain Res. 367: 96-113.

Feng, A. S., and B. A. Rogowski (1980) Effects of monaural and binaural occlusion on the morphology of neurons in the medial superior olivary nucleus of the rat. Brain Res. 189: 530-534.

Gray, L., Z. Smith, and E. W Rubel (1982) Developmental and experiential changes in dendritic symmetry in $n$. laminaris of the chick. Brain Res. 244: 360-364.

Greuel, J. M., H. J. Luhmann, and W. Singer (1987) Evidence for a threshold in experience-dependent long-term changes of kitten visual cortex. Dev. Brain Res. 34: 141-149.

Harrison, J. M., and R. Irving (1965) The anterior ventral cochlear nucleus. J. Comp. Neurol. 124: 15-42.

Harrison, J. M., and R. Irving (1966) Ascending connections of the anterior ventral cochlear nucleus in the rat. J. Comp. Neurol. 126. $51-64$. 
Heywood, C. A., L. C. L. Silveria, and A. Cowey (1988) Contrast sensitivity in rats with increased or decreased numbers of retinal ganglion cells. Exp. Brain Res. 70: 513-526.

Irvine, D. R. F. (1986) The auditory brainstem. In Progress in Sensory Physiology, 161.7, Vol. 7, Springer-Verlag, Berlin.

Jhaveri, S., and D. K. Morest (1982) Neuronal architecture in nucleus magnocellularis of the chicken auditory system with observations on nucleus laminaris: A light and electron microscope study. Neuroscience 7: 809-836.

Kelly, J. B., G. L. Kavanagh, and J. C. H. Dalton (1986) Hearing in the ferret (Mustela putorius): Thresholds for pure tone detection. Hear. Res. 24: 269-275.

Kerr, L. M., E. M. Ostapoff, and E. W Rubel (1979) Influence of acoustic experience on the ontogeny of frequency generalization gradients in the chicken. J. Exp. Psychol. Anim. Behav. Processes 5:97115 .

Killackey, H. P., and D. K. Ryugo (1977) Effects of neonatal auditory system damage on the structure of the inferior colliculus of the rat. Anat. Rec. 187: 624.

King, A. J., and M. E. Hutchings (1987) Spatial response properties of acoustically responsive neurons in the superior colliculus of the ferret: A map of auditory space. J. Neurophysiol. 57: 596-624.

King, A. J., M. E. Hutchings, D. R. Moore, and C. Blakemore (1988) Developmental plasticity in the visual and auditory representations in the mammalian superior colliculus. Nature 332: 73-76.

Kitzes, L. M. (1984) Some physiological consequences of neonatal cochlear destruction in the inferior colliculus of the gerbil. Brain Res. 306: $171-178$.

Kitzes, L. M. (1986) The role of binaural innervation in the development of the auditory brainstem. In Biology of Change in Otalar yngology, R. J. Ruben, T. N. Van De Water, and E. W Rubel (eds), Elsevier, Amsterdam.

Kitzes, L. M., and M. N. Semple (1985) Single unit responses in the inferior colliculus: Effects of neonatal unilateral cochlear ablation. J. Neurophysiol. 53: 1483-1500.

Knudsen, E. I. (1983) Early auditory experience aligns the auditory map of space in the optic tectum of the barn owl. Science 222:939942.

Knudsen, E. X. (1985) Experience alters the spatial tuning of auditory units in the optic tectum during a sensitive period in the barn owl. J. Neurosci. 5: 3094-3109.

Knudsen, E. I., P. F. Knudsen, and S. D. Esterly (1982) Early auditory experience modifies sound localization in barn owls. Nature 295:238240.

Knudsen, E. I., S. D. Esterly and P. F. Knudsen (1984a) Monaural occlusion alters sound localization during a sensitive period in the barn owl. J. Neurosci. 4: 1001-1011.

Knudsen, E. I., P. F. Knudsen, and S. D. Esterly (1984b) A critical period for recovery of sound localization accuracy following monaural occlusion in the barn owl. J. Neurosci. 4: 1012-1020.

Koerber, C., R. R. Pfeiffer, W. B. Warr, and N. Y. S. Kiang (1966) Spontaneous spike discharges from units in the cochlear nuclcus after destruction of the cochlea. Exp. Neurol. 16: 119-130.

Levi-Montalcini, R. (1949) Development of the acoustico-vestibular centers in the chick embryo in the absence of the afferent root fibers and of descending fiber tracts. J. Comp. Neurol. 91: 209-242.

Margoliash, D. (1986) Preference for autogenous song by auditory neurons in a song system nucleus of the white-crowned sparrow. $J$. Neurosci. 6: 1643-1661.

Mesulam, M.-M. (1982) Tracing Neural Connections with Horseradish Peroxidase, Wiley, Chichester, UK.

Moore, D. R. (1982) Late onset of hearing in the ferret. Brain Res. 253: 309-311.

Moore, D. R. (1983) Development of inferior colliculus and binaural audition. In Development of Auditory and Vestibular Systems, R. Romand, ed., pp. 121-166, Academic, New York.

Moore, D. R. (1988a) Auditory brainstem of the ferret: Sources of projections to the inferior colliculus. J. Comp. Neurol. 269: 342-354.

Moore, D. R. (1988b) Effects of unilateral cochlear ablation in neonatal and mature ferrets on neuron size and number in the cochlear nucleus. Soc. Neurosci. Abstr. 14: 425.

Moore, D. R., and D. R. F. Irvine (1981) Plasticity of binaural interaction in the cat inferior colliculus. Brain Res. 208: 198-202.

Moore, D. R., and L. M. Kitzes (1985) Projections from the cochlear nucleus to the inferior colliculus in normal and neonatally cochleaablated gerbils. J. Comp. Neurol. 240: 180-195.
Moore, D. R., and L. M. Kitzes (1987) Development and plasticity of neural connections between the cochlear nucleus and medial superior olive in the gerbil. Br. J. Audiol. 21: 105.

Moore, D. R., and N. E. Kowalchuk (1988) Auditory brainstem of the ferret: Effects of unilateral cochlear lesions on cochlear nucleus volume and projections to the inferior colliculus. J. Comp. Neurol. 272: 503-515.

Moore, D. R., M. N. Semple, and P. D. Addison (1983) Some acoustic properties of neurons in the ferret inferior colliculus. Brain Res. 269: 69-82.

Moore, D. R., M. N. Semple, P. D. Addison, and L. M. Aitkin (1984) Properties of spatial receptive fields in the central nucleus of the cat inferior colliculus I. Responses to tones of low intensity. Hearing Res. 13: 159-174.

Nordeen, K. W., H. P. Killackey, and L. M. Kitzes (1983) Ascending projections to the inferior colliculus following unilateral cochlear ablation in the neonatal gerbil, Meriones unguiculatus. J. Comp. Neurol. 214: 144-153.

Oliver, D. L. (1984) Dorsal cochlear nucleus projections to the inferior colliculus in the cat: A light and electron microscopic study. J. Comp. Neurol. 224: 155-172.

Oliver, D. L. (1985) Quantitative analyses of axonal endings in the central nucleus of the inferior colliculus and distribution of $3 \mathrm{H}-\mathrm{la}-$ beling after injections in the dorsal cochlear nucleus. J. Comp. Neurol. 237: 343-359.

Oliver, D. L. (1987) Projections to the inferior colliculus from the anteroventral cochlear nucleus in the cat: Possible substrates for binaural interaction. J. Comp. Neurol. 264: 24-46.

Osen, K. K. (1969) Cytoarchitecture of the cochlear nuclei in the cat. J. Comp. Neurol. 136: 453-484.

Parks, T. N. (1979) Afferent influences on development of the brain stem auditory nuclei of the chicken: Otocyst ablation. J. Comp. Neurol. 183: 665-678.

Pasic, T. R., and E. W Rubel (1987) Rapid changes in gerbil anteroventral cochlear nucleus cell size following tetrodotoxin blockade of eighth nerve activity. Soc. Neurosci. Abstr. 13: 79.

Powell, T. P. S., and S. D. Erulkar (1962) Transneuronal cell degeneration in the auditory relay nuclei of the cat. J. Anat. (Lond.) 96. 249-268.

Reale, R. A., J. F. Brugge, and J. C. K. Chan (1987) Maps of auditory cortex in cats reared after unilateral cochlear ablation in the neonatal period. Dev. Brain Res. 34: 281-290.

Rubel, E. W, and T. N. Parks (1975) Organization and development of brain stem auditory nuclei of the chicken: Tonotopic organization of N. magnocellularis and N. laminaris. J. Comp. Neurol. 164:411434.

Ryugo, D. K., and F. H. Willard (1985) The dorsal cochlear nucleus of the mouse: A light microscopic analysis of neurons that project to the inferior colliculus. J. Comp. Neurol. 242: 381-396.

Ryugo, D. K., F. H. Willard, and D. M. Fekete (1981) Differential afferent connections to the inferior colliculus from the cochlear nucleus in the albino mouse. Brain Res. 210: 342-349.

Sherman, S. M., and P. D. Spear (1982) Organization of visual pathways in normal and visually deprived cats. Physiol. Rev. 62: 738855 .

Shook, B. L., L. Maffei, and L. M. Chalupa (1985) Functional organization of the cat's visual cortex after prenatal interruption of binocular connections. Proc. Natl. Acad. Sci. USA 82: 3901-3905.

Silverman, M. S., and B. M. Clopton (1977) Plasticity of binaural interaction I. Effect of early auditory deprivation. J. Neurophysiol. 40: $1266-1274$.

Smith, Z. D. J., L. Gray, and E. W Rubel (1983) Afferent influences on brain stem auditory nuclei of the chicken: $N$. laminaris dendritic length following monaural conductive hearing loss. J. Comp. Neurol 220: 199-205

Steel, K. P., P. Moorjani, and G. R. Bock (1987) Mixed conductive and sensorineural hearing loss in LP/J mice. Hearing Res. 28: $227-$ 236.

Tonndorf, J. (1972) Bone conduction. In Foundation of Modern Auditory Theory, J. V. Tabias (ed.), Vol. 2, pp. 195-238, Academic, New York.

Trune, D. R. (1982) Influence of neonatal cochlear removal on the development of the mouse cochlear nucleus. I. Number, size and density of its neurons. J. Comp. Neurol. 209: 409-424.

Tucci, D. L., and E. W Rubel (1985) Afferent influences on brain stem auditory nuclei of the chicken: Effects of conductive and sen- 
sorineural hearing loss on $\mathrm{n}$. magnocellularis. J. Comp. Neurol. 238: 371-381.

Tucci, D. L., D. E. Born, and E. W Rubel (1987) Changes in spontaneous activity and CNS morphology associated with conductive and sensorineural hearing loss in chickens. Ann. Otol. Rhinol. Laryngol. 96: 343-350.

Wallhausser, E., and H. Scheich (1987) Auditory imprinting leads to differential 2-deoxyglucose uptake and dendritic spine loss in the chick rostral forebrain. Dev. Brain Res. 31: 29-44.

Webster, D. B. (1983) Auditory neuronal sizes after a unilateral conductive hearing loss. Exp. Neurol. 79: 130-140.

Webster, D. B. (1988) Conductive hearing loss affects the growth of the cochlear nuclei over an extended period of time. Hearing Res. 32: 185-192.

Webster, D. B., and D. R. Trune (1982) Cochlear nuclear complex of mice. Am. J. Anat. 163: 103-130.

Webster, D. B., and M. Webster (1977) Neonatal sound deprivation affects brain stem auditory nuclei. Arch. Otolaryngol. 103: 392-396.
Webster, D. B., and M. Webster (1979) Effects of neonatal conductive hearing loss on brain stem auditory nuclei. Ann. Otol. Rhinol. Laryngol. 88: 684-688.

Wiesel, T. N., and D. H. Hubel (1963a) Effects of visual deprivation on morphology and physiology of cells in the cat's lateral geniculate body. J. Neurophysiol. 26: 978-993.

Wiesel, T. N., and D. H. Hubel (1963b) Single-cell responses in striate cortex of kittens deprived of vision in one eye. J. Neurophysiol. 26: 1003-1017.

Wiesel, T. N., and D. H. Hubel (1965) Comparison of the effects of unilateral and bilateral eye closure on cortical unit responses in kittens. J. Ncurophysiol. 28: 1029-1040.

Willard, F. H., and D. K. Ryugo (1982) Anatomy of the central auditory system. In The Auditory Psychobiology of the Mouse, J. Willott, ed., Charles C Thomas, Springfield, IL. 